\title{
SimLife model: introducing a new teaching device in endocrine surgery simulation
}

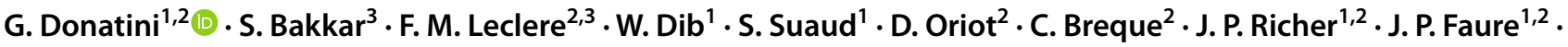 \\ J. Danion ${ }^{1,2}$
}

Received: 31 May 2020 / Accepted: 23 August 2020 / Published online: 2 September 2020

(C) Italian Society of Surgery (SIC) 2020

\begin{abstract}
To evaluate the validity and reliability of an innovative training model for endocrine surgical procedures. A simulator training model for endocrine procedures (SimLife) was developed at an academic center. The model consisted of a realistic operating environment with a coherent simulated patient dynamized by pulsatile vascularization with simulated blood warmed to $37^{\circ} \mathrm{C}$, and ventilation. Training sessions were designed for adrenal and thyroid surgery, as well as neck dissection. The primary outcome of interest was to evaluate learners' performance and satisfaction. Learners' performance was evaluated based on a scoring scale that followed the Downing method for the assessment of competency. While learners' satisfaction was evaluated using a Likert scale of 1 to 10 on four items (ease of learning, anatomic correspondence of landmarks, realism, and overall satisfaction). Participants were engaged in 32 training sessions. These included 24 adrenalectomies (conventional and laparoscopic both transabdominal and posterior), and 4 thyroid lobectomies with concomitant functional lateral compartment neck dissection. competency scores were procedure-specific addressing specific core components of a given procedure. Learners' performance scored above average in all procedures evaluated. Satisfaction scores for the specified four items ranged between 8.43 (SD 0.87) and 8.89 (SD 0.96). No major events were reported for the adrenalectomies, while only one jugular vein injury occurred during neck dissection. SimLife is a hyper-realistic training model that allows for satisfactory acquisition of skills and the evaluation of performance progression. It has the potential to become a cornerstone in specialized surgical training.
\end{abstract}

Keywords Endocrine surgery $\cdot$ Surgical training $\cdot$ Simulator $\cdot$ Model $\cdot$ SimLife

\section{Introduction}

Subspecialization in Endocrine Surgery, as in other surgical disciplines, aims to yield surgeons with an adequate level of proficiency and safety in performing various procedures

Electronic supplementary material The online version of this article (https://doi.org/10.1007/s13304-020-00871-x) contains supplementary material, which is available to authorized users.

G. Donatini

giacko76@hotmail.com

1 Department of General Surgery, University of Poitiers, CHU Poitiers, Poitiers, France

2 ABS Lab, School of Medicine, University of Poitiers, Poitiers, France

3 Department of Surgery, Faculty of Medicine, The Hashemite University, Zarqa 13133, Jordan independently and competently following a proper learning curve [1-7]. As performance tends to improve with experience, a trainee's volume or annual caseload becomes the cornerstone of any given surgical educational program [1, 3-9]. It has also been demonstrated that trainees considerably benefit from surgical simulation [9-11]. The essence of surgical simulation is to expose trainees to real-time intheater experiences without compromising patient safety.

"Primum non nocere" or "first do no harm" has always been the motto in Medicine. The rapid evolution in surgical disciplines and the advent of contemporary procedures has rendered the Halstedian model of apprenticeship "see one, do one, teach one" inadequate [12]. Therefore, there is a continuous need for methods that allow for sufficient mentored-hands-on training without compromising patient safety. Surgical simulation provides the opportunity of supervised learning for trainees, allowing full mastering of technical skills prior to actual practice on patients following 
the pedagogical principles of Kirkpatrik's pyramid of training evaluation (Fig. 1) [10, 11, 13, 14] For this reason, the Anatomy, Biomechanics and Simulation Laboratory (ABS Lab) of Poitiers' University developed a hyper-realistic training model for specialized surgical procedures. The innovative training model was named "SimLife" $[15,16]$. It uses a pulsated revascularized and reventilated cadaver donated for surgical education.

The purpose of this study is to validate SimLife as a training model in highly specialized endocrine surgical procedures. As well as its reliability as a tool for assessing performance and its progression.

\section{Materials and methods}

\section{The training model (SimLife)}

The innovative training model was developed at the ABS lab of Poitiers' University $[15,16]$. The model consists of a human cadaver prepared for surgical simulation. It is dynamized by pulsatile vascularization with simulated blood warmed to $37{ }^{\circ} \mathrm{C}$ and is ventilated. Bodies donated to science are retrieved from the body donation center of Poitiers' University. The body typically arrives within $48 \mathrm{~h}$ following demise. However, arrival time has been reduced to less than $24 \mathrm{~h}$ as per SimLife protocol to achieve timing optimality [16]. The body is then assigned a traceable number but remains anonymous. Any human body with one of the following criteria is excluded from SimLife: body mass index (BMI) $\geq 25 \mathrm{~kg} / \mathrm{m}^{2}$, previous major surgery (cervical, thoracic and/or abdominal), and possible contamination including HIV, HBV, HCV, Creutzfeldt-Jacob, Tuberculosis and most recently the COVID-19 [15-17].

Once all inclusion criteria are fulfilled, the cadaver is technically prepared as a training model. Vascular cleansing is performed with water at low pressure $(0.8$ bar $)$ at a maximum temperature of $30^{\circ} \mathrm{C}$. This is achieved by means of cannulas placed in both femoral arteries (input) and both femoral veins (output) (Fig. 2). Subsequently, external body cleaning and disinfection is performed, and the corpus is freezed at $22{ }^{\circ} \mathrm{C}$ in a negative pressure cold room $[15,16]$. Upon scheduling a training session, the corpus is defrosted at $16{ }^{\circ} \mathrm{C}$, over several days. Ventilation is achieved by means of orotracheal intubation and the stomach is emptied by a nasogastric tube. The model is then tested for physiological data.

The specific technical module P4P (Pulse for Practice, patent no. 1000318748 deposited by Poitiers' University, INSERM and CNRS international extension PCT/ EP2016/075819 published on 2017/05/11, WO 2017/076717 A1) animates the living human body. It is perfused by bloodmimicking fluid (patent L18217) circulating in the arterial system in a pulsating manner, recoloring and warming internal organs to $37^{\circ} \mathrm{C}$, and restoring venous turgor. Physiological hemodynamic data are computer monitored continuously
Fig. 1 Kirkpatrick's pyramid of training evaluation

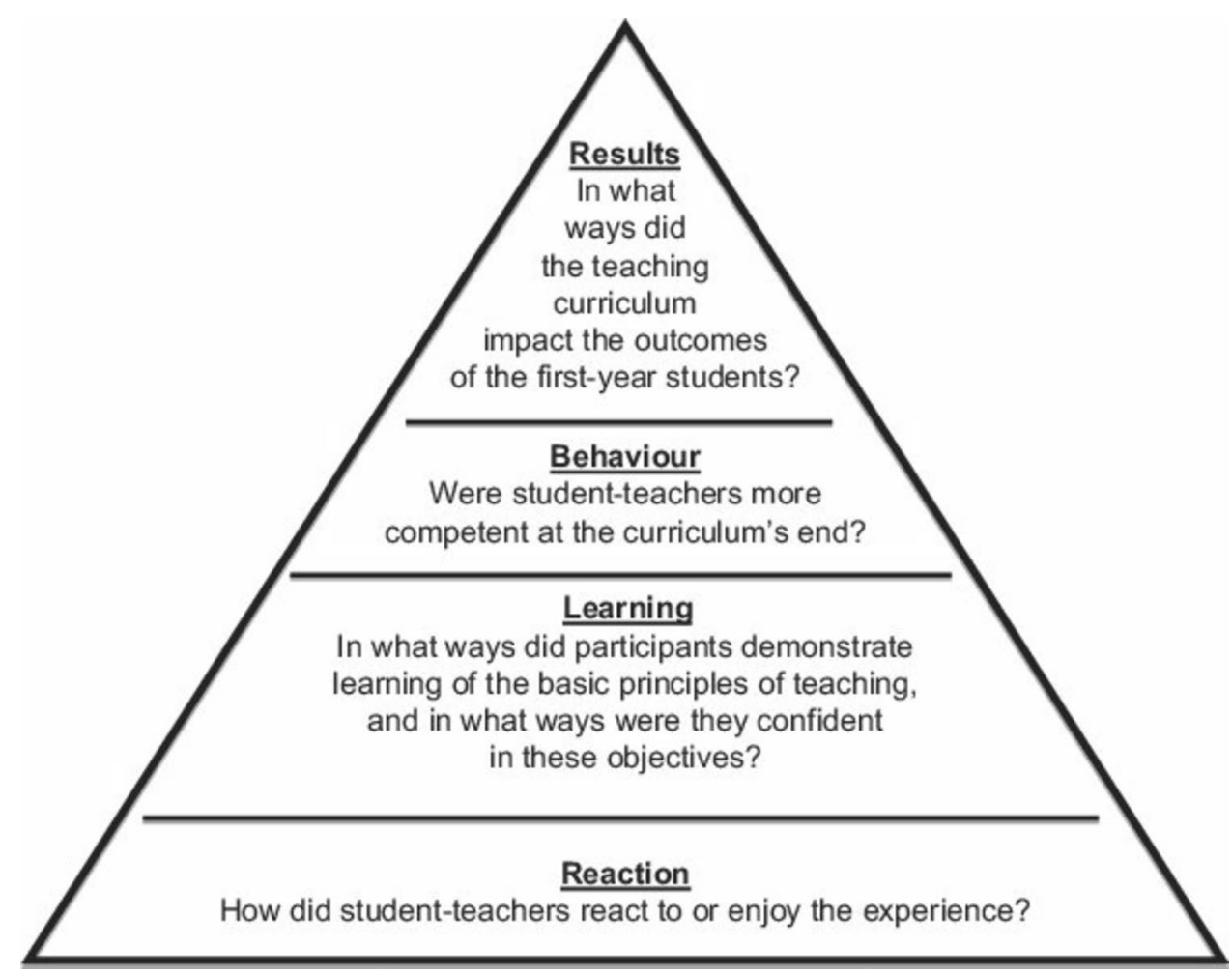




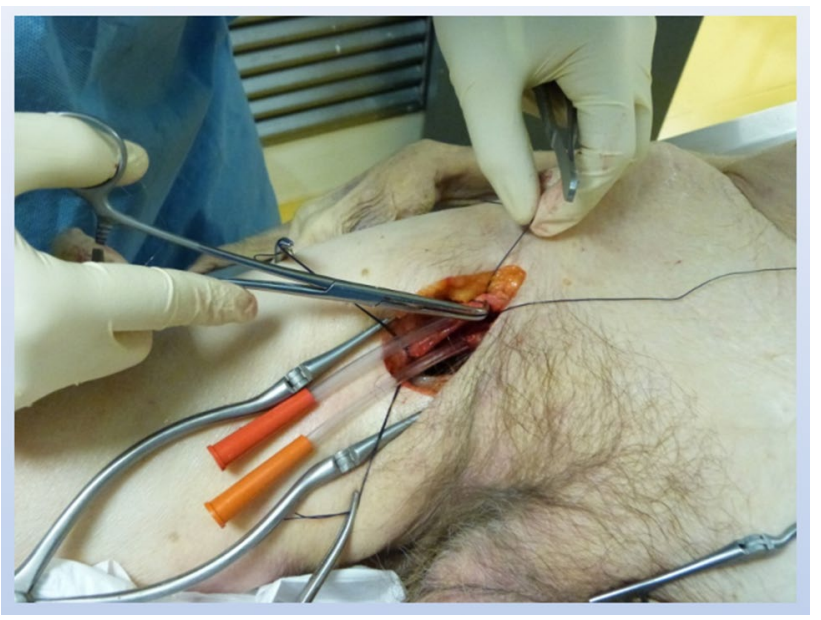

Fig. 2 Body's preparation to become a SimLife model

and adapted as needed, with the vital signs fluctuating as per real in-theater possible scenarios. The P4P module is a specifically dedicated software that is responsive to potential adverse intraoperative scenarios mimicking real-life situations such as hemorrhage, ... etc.

The learning platform on the cadaveric model has been approved by the French Ministry of Health Ethics Committee (protocol number DC-2008-137). Data collection and analysis were performed according to the institutional guidelines and the ethical standards of the Helsinki Declaration.

\section{Evaluation of learners' performance}

Simulation is part of the method and practice of academic surgical teaching. This mandates the presence of an objective scale for evaluating the acquisition of knowledge and skills. A scoring scale that allows for evaluating performance was designed and validated by six French national experts in endocrine surgery following the Downing method for the assessment of competency [18]. The prescale was created using the nominal group method. It was then tested on six senior surgeons, nationally recognized as experts in endocrine surgery. The final scoring scale was psychometrically assessed through evaluating a population of trainees of variable levels of experience. To construct a uniform objective scale, each surgical procedure was broken down into essential executional steps. A scoring system was then applied evaluating task fulfillment. The points given ranged from -3 to 1 . Item specific scoring gives a trainee 1 point when the task is executed correctly, and penalties the trainee ( -1 to -3 points) in case of a surgical fault. Specific scoring scales were designed for each of the specified procedures (adrenal surgery, thyroid surgery, and neck dissection). The scale for each procedure varies according to its essential executional steps. Figure 3 demonstrates the application of the scale for right transperitoneal adrenalectomy as an example.

\begin{tabular}{|c|c|c|c|c|}
\hline Surrénalectomie Gauche par Laparotomie & & & & Note sur Item \\
\hline \multirow[t]{4}{*}{ Verification installation patient } & \begin{tabular}{|l|l} 
Patient decubitus dorsal \\
\end{tabular} & Oui & Non & 1 \\
\hline & Billot sous le flanc gauche & Oui & Non & 1 \\
\hline & angle entre axe horizontal de la table et ligne d'épaules du patient de $45^{\circ}$ (voir dessin briefing) & Oui & Non & 1 \\
\hline & Bras droit en croix, le gauche le long du corps & Oui & Non & 1 \\
\hline \multirow[t]{3}{*}{ Répères anatomiques marqués (dessinés sur la peau) } & Bord sub costal & Oui & Non & 1 \\
\hline & ombilic & Oui & Non & 1 \\
\hline & crete iliaque & Oui & Non & 1 \\
\hline
\end{tabular}

MISE EN CIRCULATION DU SIM LIFE

\begin{tabular}{|c|c|c|c|c|}
\hline \multirow[t]{9}{*}{ Laparotomie } & Incision sous-costale gauche & \multirow{9}{*}{$\begin{array}{l}\text { Oui } \\
\text { Oui } \\
\text { Oui } \\
\text { Oui } \\
\text { Oui } \\
\text { Oui } \\
\text { Oui } \\
\text { Oui } \\
\text { Oui } \\
\end{array}$} & Non & 1 \\
\hline & 2 travers de doigts sous les cotes & & Non & 1 \\
\hline & Debut: bord médial du muscle grand droit de droite $( \pm 2 \mathrm{~cm})$ & & Non & 1 \\
\hline & Fin: ligne axillaire moyenne gauche $( \pm 2 \mathrm{~cm})$ & & Non & 1 \\
\hline & Section plan par plan des muscle antéro-lateraux de l'abdomen & & Non & 1 \\
\hline & Incision du péritoine parietal & & Non & 1 \\
\hline & Plaie grelique & & Non & $0 /-1$ \\
\hline & Plaie omentum & & Non & $0 /-1$ \\
\hline & Plaie colique & & Non & $0 /-1$ \\
\hline \multirow[t]{2}{*}{ exploration } & Section du ligament rond hépatique & Oui & Non & 1 \\
\hline & Exploration de la cavité abdominale (recherche d'epanchement libre et/ou carcinose) & Oui & Non & 1 \\
\hline \multirow[t]{3}{*}{ mobilisation angle colique gauche } & decolement colo epiploique & Oui & Non & 1 \\
\hline & liberation des ligaments splenocoliques & Oui & Non & 1 \\
\hline & libération adhérences pariétales du colon descendant de haut en bas & Oui & Non & 1 \\
\hline \multirow[t]{3}{*}{ creation du tunnel de dissection } & Ecartement du bloc splénopancréatique & Oui & Non & 1 \\
\hline & liberation des ligaments spleno-diaphragmatiques & Oui & Non & 1 \\
\hline & jusqu'à visualisation du fundus gastrique & Oui & Non & 1 \\
\hline \multirow[t]{5}{*}{ traumatisme lors de la dissection } & plaie splénique & Oui & Non & $1 /-1$ \\
\hline & hemostase bipolaire & Oui & Non & -1 \\
\hline & hemostase par compression & Oui & Non & -1 \\
\hline & echec hemostase : splénectomie & Oui & Non & -3 \\
\hline & plaie glande pancreatique & Oui & Non & $0 /-1$ \\
\hline
\end{tabular}

Fig. 3 Performance evaluation scale (right anterior laparoscopic adrenalectomy) 
The evaluation was performed by two external observers to determine both the scale's validity (consistency) and reliability (interobserver reproducibility).

This method allowed teachers to objectively evaluate single-surgeon performance and progression of performance in specified endocrine procedures.

\section{Evaluation of learners' satisfaction}

At the end of each training session, trainees were asked to anonymously complete a survey indicating their degree of satisfaction by a Likert Scale from 0 to 10 on the following 4 items: the ease of learning a specific surgical procedure using SimLife, the accuracy of anatomic landmarks in SimLife, the degree of realism of SimLife, and overall satisfaction with the training SimLife.

\section{Statistical analysis}

Statistical analysis was performed by means of SAS 9.3 software. Values are reported as means and Standard deviations (SD).

\section{Results}

A total of 32 training sessions using the SimLife simulator model were hosted by the ABS lab of the medical school of Poitiers' University. The training sessions included 24 adrenal surgeries, 4 thyroid surgeries, and 4 therapeutic functional lateral compartment neck dissections. Adrenal surgeries included conventional (open) adrenalectomy $(n=8)$, laparoscopic anterior and posterior adrenalectomy $(n=8$ each). While thyroid surgeries were in the form of a hemithyroidectomy with a concomitant therapeutic functional lateral compartment neck dissection. Artificial lymph node metastases were created on SimLife by injecting specific material (data not disclosed, material under patent demand) and was identifiable on preoperative neck ultrasound (Figs. 4, 5). Hands-on training was preceded by an interactive theoretical session that introduced SimLife and educational material on the specified endocrine procedures. As performance scoring scales are procedure specific, results are provided in Table 1 for each procedure. For open adrenalectomy, scores ranged between 22 and 28 out of 37 . For posterior laparoscopic adrenalectomy, scores ranged between 24 and 29 out of 34 . Whereas for anterior laparoscopic adrenalectomy scoring scales were also side dependent; ranging between 17 and 20 out of 25 for right sided procedures, and 17-22 out of 30 for left sided procedures. Hemithyroidectomy scores ranged between 10 and 12 out of 15 (Fig. 6). Finally, lateral

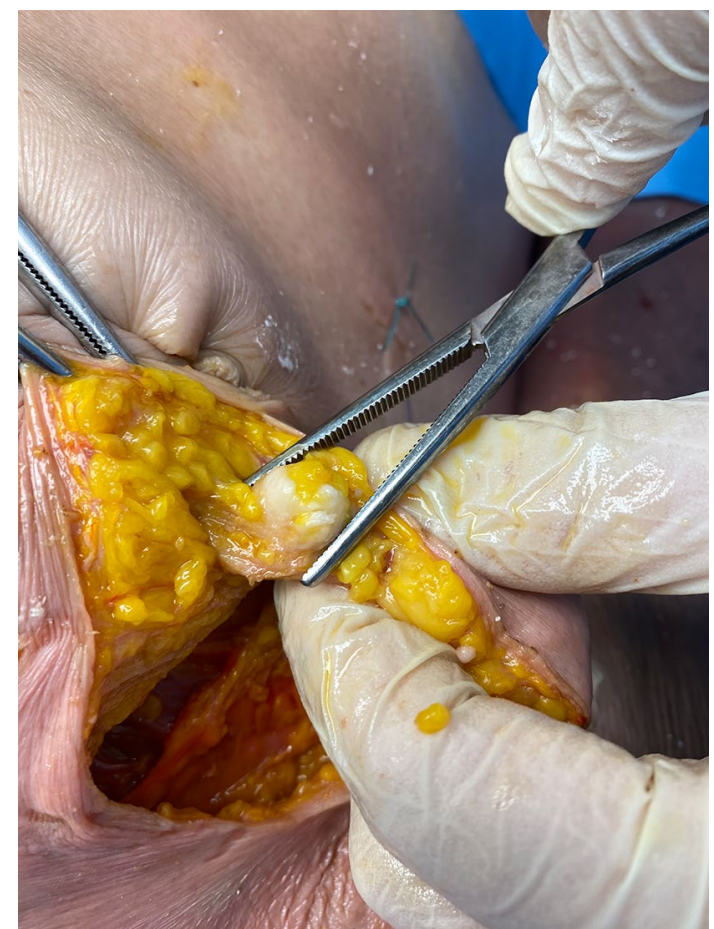

Fig. 4 Artificial lymph-node metastasis

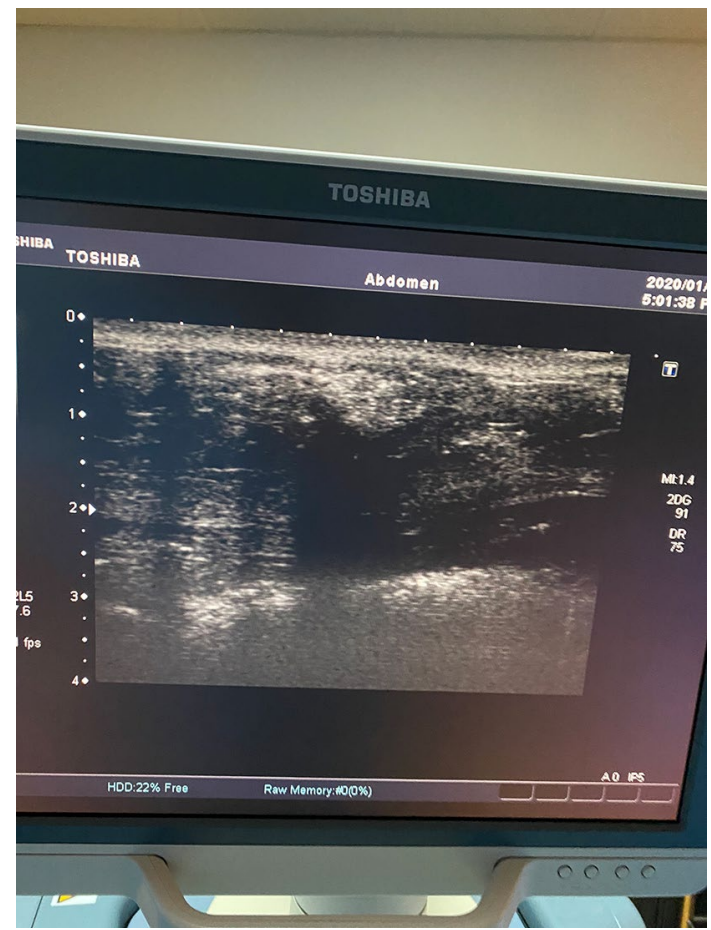

Fig. 5 Ultrasound appearance of artificial lymph nodes metastases 
Table 1 Performance scores for specific procedures

\begin{tabular}{|c|c|c|c|c|c|c|}
\hline \multicolumn{7}{|c|}{ Adrenal surgery } \\
\hline Type/score & ROA (34) & LOA (34) & RALA (25) & LALA (30) & RPLA (37) & LPLA (37) \\
\hline & 28 & 28 & 18 & 21 & 24 & 23 \\
\hline & 29 & 27 & 18 & 19 & 22 & 20 \\
\hline & 26 & 29 & 20 & 17 & 22 & 28 \\
\hline & 24 & 26 & 17 & 22 & 28 & 26 \\
\hline Mean (SD) & $26.75(3.84)$ & $27.5(2.35)$ & $18.25(0.63)$ & $19.75(1.92)$ & $24(2.45)$ & $24.25(6.06)$ \\
\hline \multicolumn{7}{|c|}{ Hemithyroidectomy (HT) and lateral compartment neck dissection (LCND) } \\
\hline \multirow[t]{5}{*}{ Type/score } & & HT & & Right LCND & & Left LCND \\
\hline & & 10 & & 11 & & - \\
\hline & & 11 & & 10 & & - \\
\hline & & 11 & & - & & 8 \\
\hline & & 12 & & - & & 11 \\
\hline Mean (SD) & & $11(1.12)$ & & $10.5(0.5)$ & & $9.5(1.5)$ \\
\hline
\end{tabular}

$R O A$ right open adrenalectomy, $L O A$ left open adrenalectomy, $R A L A$ right anterior laparoscopic adrenalectomy, $L A L A$ left anterior laparoscopic adrenalectomy, $R P L A$ right posterior laparoscopic adrenalectomy, $L P L A$ left posterior laparoscopic adrenalectomy

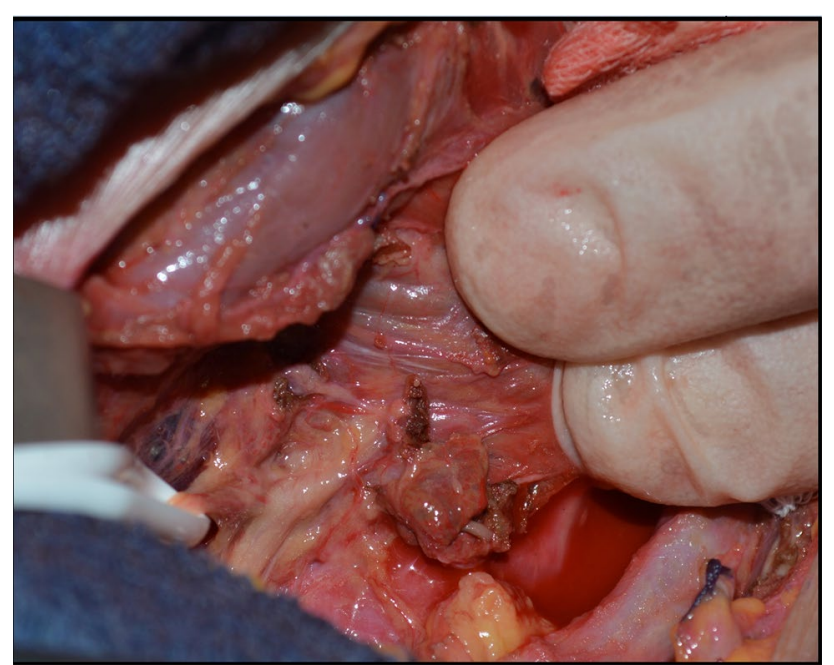

Fig. 6 Thyroid lobectomy: recurrent laryngeal nerve and parathyroids

compartment neck dissection score was out of 15 and ranged between 8 and 11 among trainees (Fig. 7). No major events were reported for the adrenalectomies, while only one jugular vein injury occurred during neck dissection. Satisfaction scores for the specified four items ranged between 8.43 (SD 0.87 ) and 8.89 (SD 0.96) (Table 2).

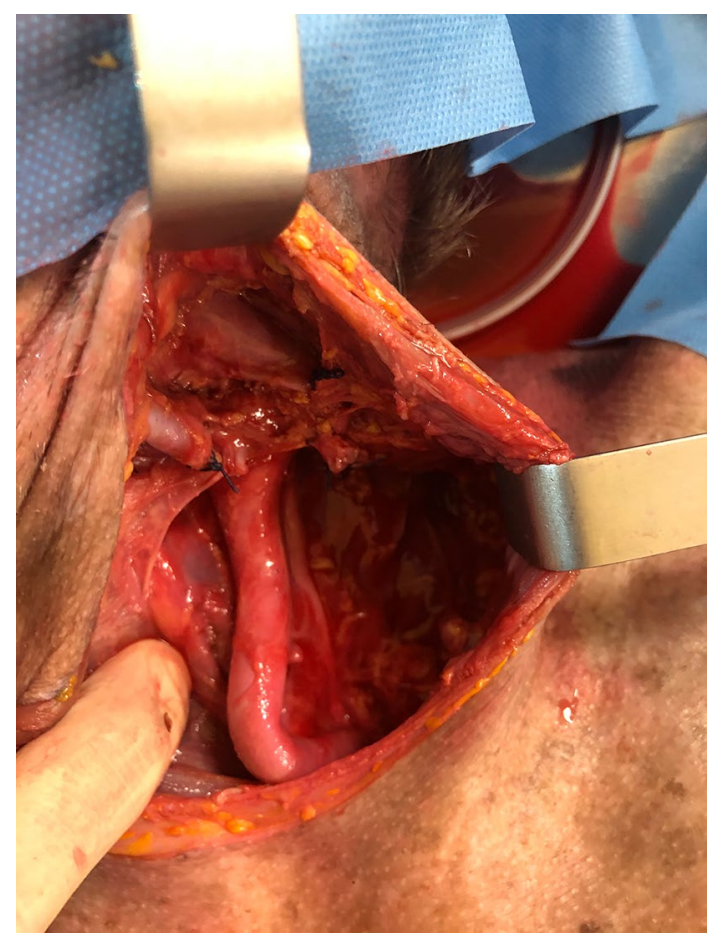

Fig. 7 Left Neck dissection. End of procedure

Table 2 Trainee's answers $(n=20)$ to evaluation questionnaire (Likert Scale 0 to 10) regarding SimLife model

\begin{tabular}{ll}
\hline Question & Score, Mean (SD) \\
\hline Learning a procedure with SimLife & $8.87(0.86)$ \\
Anatomic landmark correspondence & $8.65(0.98)$ \\
Realism of SimLife model & $8.89(0.96)$ \\
Overall satisfaction of training & $8.43(0.87)$ \\
\hline
\end{tabular}




\section{Discussion}

As in other disciplines of surgery, endocrine surgical training aims to yield surgeons that are competent in the field. However, this goal is not always achieved. A recent analysis of endocrine surgical training across 22 European countries demonstrated below-expected scores of performances for thyroid surgery and lateral neck dissection [1]. The expected median values for thyroidectomy and neck dissection were 10 and 2, respectively. While the actual values obtained were disappointingly 0 and 0.5 , respectively. Adrenal surgery training was difficult to assess as only 3 centers across Europe responded, reporting a median of 5 open and 5 minimally invasive procedures dedicated for surgeons in training per annum. Two surveys conducted by the American Association of Endocrine Surgeons (AAES) reported that surgical residents performed 2 neck dissection procedures prior to their graduation, while clinical fellows in endocrine surgery performed 6-15 procedures during their 2-year fellowship program with 12 procedures being the cut-off number of procedures required to obtain competency [3, 4]. Mihai et al. recently analyzed the current practice in adrenal surgery worldwide [5]. The results reported were far from being encouraging. Only few centers reported a consistent annual caseload, whereas most centers performed less than 5 procedures per year. These results were consistent with the findings of Palazzo et al., who analyzed the annual practice of adrenal surgery in the UK in 2013-2014 [6]. They reported that only $16 \%$ of surgeons performed $\geq 6$ adrenalectomies per year, whereas the remainder performed a median of one adrenalectomy only. Collectively, these data reflect an insufficient annual caseload of adrenal surgery during specialized training. Furthermore, the literature demonstrates that competency in minimally invasive adrenal surgery is achieved at roughly, 30 procedures. While 20 and 15 procedures are required to attain proficiency in performing thyroid surgery and neck dissection, respectively $[1,3,4]$. In the context of these figures, the need emerges for novel resources that help achieve the purpose of any subspecializing training in surgery. Simulation could potentially serve as a core component of the modern surgical apprentice [10, 11, 13, 19]. It aims to ameliorate the technical skills of trainees enhancing their overall performance as reported by Kirkpatrik's pyramid of training evaluation [14]. Simulation has the advantage of allowing for the repetition of technical gestures without compromising the safety of a living human being. This in turn allows trainees to detect and analyze errors and familiarizes them with the way of solving critical intraoperative situations $[10,11,13,19]$.

Surgical simulators could be broadly classified into two categories: synthetic and organic [10, 19]. The former includes plastic, rubber or latex-based simulators, virtual reality, and computer-based simulators. The main drawback of synthetic simulators is that they lack realistic resemblance to living beings [10]. Organic simulators, on the other hand, are subclassified into animal- and human-based models. These provide high-fidelity working environments. However, are potentially subject to restrictive measures that vary from one country to another [10, 19]. Human cadaverbased models, the oldest models available, are considered the best models for surgical training [10, 19-31]. Nevertheless, their major drawback is that they are static and do not provide real-time dynamic in-theater clinical scenarios [10, 19-26]. To overcome this issue, a perfused cadaveric model that offers a hyper-realistic working environment have been introduced [27-31]. SimLife is an organic dynamic simulator that provides the pedagogical items of surgical simulation with the highest possible degree of resemblance to reality, but, away from the patient. Our results indicate that trainees performed well in terms of skill acquisition. Furthermore, a good level of trainee satisfaction was obtained. This certainly implies the potential for further progress in performance.

There are some limitations of SimLife that need to be highlighted. First, the model was set for senior trainees. Junior trainees would benefit more from simpler types of models. Second, the number of annual sessions made available relies on the availability of cadavers. Therefore, any limitation in resources would reflect on annual caseload. Third, the revascularized model lacks hemostatic mechanisms. Therefore, intraoperative hemostasis cannot be achieved in contrast to real life. Finally, the model is costly. The mean cost per human body used, independent from the type of procedure, is about 2000 euros. Moreover, a specific dedicated budget needs to be dedicated for the P4P power module that runs the SimLife system (www.simedys.com).

\section{Conclusion}

SimLife is a hyper-realistic training model that allows for the satisfactory acquisition of skills and the evaluation of performance progression. It has the potential to overcome the pitfalls of subspecialized surgical training programs and become a core component of trainee's curriculum.

Author contributions All authors equally contributed to the study concept and design, data interpretation, drafting, final approval, and accountability for all aspects of the work.

Funding This study was not funded by any grant.

Data availability statement The data supporting the findings of this study are available from the corresponding author upon request. 


\section{Compliance with ethical standards}

Conflict of interest C Breque, D Oriot, JP Richer and JP Faure are patent co-owners of the $\mathrm{P} 4 \mathrm{P}$ device which allows the revascularization and re-ventilation of the corps. All others authors declare that they have no conflict of interest.

Ethical approval the learning platform on the cadaveric model has been approved by the French Ministry of Health Ethics Committee (protocol number DC-2008-137). Data collection and analysis were performed according to the institutional guidelines and the ethical standards of the Helsinki Declaration.

Informed consent Informed consent was waived because of the nature of this study.

\section{References}

1. Gimm O, Barczyński M, Mihai R, Raffaelli M (2019) Training in endocrine surgery. Langenbecks Arch Surg 404(8):929-944. https ://doi.org/10.1007/s00423-019-01828-4Epub 2019 Nov 7

2. Bakkar S, Materazzi G, Biricotti M, De Napoli L, Conte M, Galleri D, Aghababyan A, Miccoli P (2016) Minimally invasive video-assisted thyroidectomy (MIVAT) from A to Z. Surg Today 46:255-259

3. Sosa JA, Wang TS, Yeo HL et al (2007) The maturation of a specialty: workforce projections for endocrine surgery. Surgery 142:876-883

4. Solorzano CC, Sosa JA, Lechner SC et al (2010) Endocrine surgery: where are we today? A national survey of young endocrine surgeons. Surgery 147:536-541

5. Mihai R, Donatini G, Vidal O, Brunaud L (2019) Volumeoutcome correlation in adrenal surgery-an ESES consensus statement. Langenbecks Arch Surg 404:795-806. https://doi. org/10.1007/s00423-019-01827-5

6. Palazzo F, Dickinson A, Phillips B et al (2016) Adrenal surgery in England: better outcomes in high-volume practices. Clin Endocrinol (Oxf) 85:17-20

7. Phitayakorn R, Kelz RR, Petrusa E et al (2017) Expert consensus of general surgery residents' proficiency with common endocrine operations. Surgery 161:280-288

8. Bakkar S, Papavramidis TS, Aljarrah Q, Materazzi G, Miccoli P (2020) Energy-based devices in thyroid surgery-an overview. Gland Surg 9(Supp 1):S14-S17. https://doi.org/10.21037 Igs.2019.08.05

9. Fronza JS, Prystowsky JP, DaRosa D et al (2012) Surgical residents' perception of competence and relevance of the clinical curriculum to future practice. J Surg Educ 69:792-797

10. Tan SS, Sarker SK (2011) Simulation in surgery: a review. Scott Med J 56:104-109. https://doi.org/10.1258/smj.2011.011098

11. Zahiri HR, Park AE, Pugh CM, Vassiliou M, Voeller G (2015) "See one, do one, teach one": inadequacies of current methods to train surgeons in hernia repair. Surg Endosc 29:2867-2872. https ://doi.org/10.1007/s00464-015-4411-7

12. Scott DJ, Cendan JC, Pugh CM, Minter RM, Dunnington GL, Kozar RA (2008) The changing face of surgical education: simulation as the new paradigm. J Surg Res 147:189-193

13. Ziv A, Small SD, Wolpe PR (2000) Patient safety and simulationbased medical education. Med Teacher 22:489-495

14. Kirkpatrick DL, Kirkpatrick JD (2006) Evaluating training programs: the four levels. Berrett-Koehler, San Francisco, p 379

15. Delpech PO, Danion J, Oriot D, Richer JP, Breque C, Faure JP (2017) SimLife a new model of simulation using a pulsated revascularized and reventilated cadaver for surgical education. J Visc Surg 154:15-20. https://doi.org/10.1016/j.jvisc surg.2016.06.006

16. Faure JP, Breque C, Danion J, Delpech PO, Oriot D, Richer JP (2017) SIM Life: a new surgical simulation device using a human perfused cadaver. Surg Radiol Anat 39:211-217

17. Al-Omar K, Bakkar S, Khasawneh L, Donatini G, Miccoli P (2020) Resuming elective surgery in the time of COVID-19: a safe and comprehensive strategy. Updates Surg. https://doi. org/10.1007/s13304-020-00822-6[ahead of print]

18. Downing SM (2003) Validity: on the meaningful interpretation of assessment data. Med Educ 37:830-837

19. Sarker SK, Patel B (2007) Simulation and surgical training. Int J Clin Pract 61:2120-2125

20. James HK, Chapman AW, Pattison GTR, Griffin DR, Fisher JD (2019) Systematic review of the current status of cadaveric simulation for surgical training. Br J Surg 106:1726-1734. https://doi. org/10.1002/bjs. 11325

21. Kim SC, Fisher JG, Delman KA, Hinman JM, Srinivasan JK (2016) Cadaver-based simulation increases resident confidence, initial exposure to fundamental techniques, and may augment operative autonomy. J Surg Educ 73:e33-e41. https://doi. org/10.1016/j.jsurg.2016.06.014

22. Aydin A, Ahmed K, Khan MS, Dasgupta P, McCabe J (2015) The role of human cadaveric procedural simulation in urology training. J Urol 193:e273

23. Weber EL, Leland HA, Azadgoli B, Minneti M, Carey JN (2017) Preoperative surgical rehearsal using cadaveric fresh tissue surgical simulation increases resident operative confidence. Ann Transl Med 5:302

24. Reed AB, Crafton C, Giglia JS, Hutto JD (2009) Back to basics: use of fresh cadavers in vascular surgery training. Surgery 146:757-763

25. Chouari TAM, Lindsay K, Bradshaw E, Parson S, Watson L, Ahmed J et al (2018) An enhanced fresh cadaveric model for reconstructive microsurgery training. Eur J Plast Surg 41:439-446

26. Sharma M, Macafee D, Horgan AF (2013) Basic laparoscopic skills training using fresh frozen cadaver: a randomized controlled trial. Am J Surg 206:23-31

27. Pham M, Kale A, Marquez Y, Winer J, Lee B, Harris B et al (2014) A perfusion-based human cadaveric model for management of carotid artery injury during endoscopic endonasal skull base surgery. J Neurol Surg B Skull Base 75:309-313

28. Pacca P, Jhawar SS, Seclen DV, Wang E, Snyderman C, Gardner PA et al (2017) 'Live cadaver' model for internal carotid artery injury simulation in endoscopic endonasal skull base surgery. Oper Neurosurg (Hagerstown) 13:732-738

29. Ciporen JN, Lucke-Wold B, Mendez G, Cameron WE, McCartney $S$ (2017) Endoscopic management of cavernous carotid surgical complications: evaluation of a simulated perfusion model. World Neurosurg 98:388-396

30. Strickland BA, Ravina K, Kammen A, Chang S, Rutkowski M, Donoho DA, Minneti M, Jackanich A, Bakhsheshian J, Zada G (2020) The use of a novel perfusion based human cadaveric model for simulation of dural enous injury and repair. Oper Neurosurg (Hagerstown). https://doi.org/10.1093/ons/opz424

31. Gnanakumar S, Kostusiak M, Budohoski KP, Barone D, Pizzuti V, Kirollos R, Santarius T, Trivedi R (2018) Effectiveness of cadaveric simulation in neurosurgical training: a review of the literature. World Neurosurg 118:88-96. https://doi.org/10.1016/j. wneu.2018.07.015

Publisher's Note Springer Nature remains neutral with regard to jurisdictional claims in published maps and institutional affiliations. 